\title{
OS DEFENSORES DOS DIREITOS HUMANOS FRENTE AS CLASSES SUBALTERNAS
}

\author{
Paulo Merli Franco*
}

\begin{abstract}
RESUMO: O artigo problematiza a posição dos defensores dos Direitos Humanos diante das classes subalternas. Adota como referencial um paradigma que combina a filosofia da práxis de Gramsci com a pedagogia libertadora de Paulo Freire. Desenvolvendo uma concepção contra-hegemônica dos Direitos Humanos baseada na historicidade; na igualdade e reconhecimento da diferença; na comunicação e dialogicidade; no horizonte utópico da sociedade regulada.
\end{abstract}

Palavras-chave: Defensores dos direitos humanos; Classes subalternas; Concepção contra-hegemônica.

ABSTRACT: The article problematizes the position of the Human Rights defenders front the subaltern classes. Adopts a paradigm as reference that combines the philosophy of praxis of Gramsci with the liberating pedagogy of Paulo Freire. Developing a counter-hegemonic conception of human rights based on the historicity; philosophy of praxis; equality and recognition of difference; communication and dialogicity; utopian horizon of regulated society.

Keywords: Human rights defenders; Subaltern classes; Counter-hegemonic conception.

\section{INTRODUÇÃO}

Os defensores dos Direitos Humanos e seus defensores precisam se posicionar diante das classes sociais, historicamente, existentes.

Como bem afirmou Gramsci (2004a, p. 84),

Creio [...] que 'viver é tomar partido'. Não podem existir os que são apenas homens, os estranhos à cidade. Quem vive verdadeiramente não pode deixar de ser cidadão e de tomar partido. Indiferença é abulia, é parasitismo, é covardia, não é vida. Por isso, odeio os indiferentes.

\footnotetext{
“ Graduação em Direito pela Universidade Estadual Paulista “Júlio de Mesquita Filho” (Unesp) Campus de Franca. Membro do Seminário Gramsci (Ribeirão Preto) e do Núcleo de Estudos de Direito Alternativo (Unesp). Foi advogado do Centro de Direitos Humanos e Educação Popular de Ribeirão Preto (CEDHEP). Membro da Comissão de Direitos Humanos da $12^{\mathrm{a}}$ Subseção de Ribeirão Preto da OAB-SP (2010-2012), conselheiro titular no Conselho Municipal dos Direitos da Criança e do Adolescente de Ribeirão Preto e conselheiro suplente no Conselho Municipal de Moradia Popular de Ribeirão Preto pela $12^{\text {a }}$ Subseção de Ribeirão Preto da OAB-SP (2011-2012). E-mail: pmerlifranco@yahoo.com.br
} 
Como fica, então, a posição dos defensores dos Direitos Humanos diante das classes sociais existentes? A universalidade dos Direitos Humanos pode ser confundida com neutralidade e/ou indiferença em relação ao conflito histórico entre as classes sociais fundamentais?

É preciso se posicionar perante tais questionamentos. Os defensores dos Direitos Humanos precisam desenvolver um saber-fazer voltado às classes subalternas. Um dos caminhos teórico-prático para fugir de uma posição de neutralidade e/ou indiferença, em relação ao conflito histórico entre as classes sociais fundamentais, pode ser o paradigma da filosofia da práxis.

Para Gramsci (2006a, p. 388),

\begin{abstract}
A filosofia da práxis, ao contrário, não tende a resolver pacificamente as contradições existentes na história e na sociedade, ou, melhor, ela é a própria teoria de tais contradições; não é instrumento de governo de grupos dominantes para obter o consentimento e exercer a hegemonia sobre as classes subalternas; é a expressão destas classes subalternas, que querem educar a si mesmas na arte de governo e que têm interesse em conhecer todas as verdades, inclusive as desagradáveis, e em evitar enganos (impossíveis) da classe superior, e, ainda mais, de si mesmas.
\end{abstract}

Outro ponto muito importante, é reconhecer a necessidade dos educadores populares em Direitos Humanos trabalharem, simultaneamente, com os princípios da igualdade e do reconhecimento da diferença, sintetizado de modo primoroso por Boaventura de Sousa Santos (2003, p. 56) no aforismo: "temos direito a ser iguais quando a nossa diferença nos inferioriza; e temos o direito a ser diferentes quando a nossa igualdade nos descaracteriza".

Outra questão essencial é como lidar com o conhecimento em um projeto de assessoria jurídica e educação popular em Direitos Humanos. Primeiramente, é imprescindível reconhecer o outro como igual numa relação de horizontalidade, apesar das diferenças subjetivas inerentes à natureza humana. Olhar o outro nos olhos, nunca, jamais de cima para baixo.

$\mathrm{Na}$ sua emocionante carta testamento, Gabriel García Márquez deixa uma bela lição: "aprendi que um homem só tem direito a olhar o outro de cima 
para baixo, quando vai ajudá-lo a levantar-se".

A relação com o subalterno deve ser de aproximação dialógica e comunicativa, com intuito de compartilhar os conhecimentos seus e dele, numa relação pedagógica, onde ambos são - ao mesmo tempo - educadoreducando e educando-educador. Desenvolvendo um trabalho conjunto e coletivo, que busque e construa democrática e horizontalmente os caminhos e as possíveis soluções para as demandas populares.

Segundo Paulo Freire (1977, p. 78),

\begin{abstract}
Esta é a razão pela qual, para nós, a "educação como prática de liberdade" não é a transferência ou a transmissão do saber nem da cultura; não é a extensão de conhecimentos técnicos; não é o ato de depositar informes ou fatos nos educandos; não é a "perpetuação dos valores de uma cultura dada", não é o "esfôrço de adaptação do educando a seu meio".
\end{abstract}

A luta dos militantes dos Direitos Humanos, a favor e lado a lado das classes subalternas, devem se preocupar em dar voz e vez ao grito dos oprimidos, colaborando no sentido de empoderar os oprimidos, para sua tomada de consciência da realidade mediatizada e de emancipação da condição de invisibilidade e vulnerabilidade sociais.

O trabalho em conjunto com os oprimidos necessita também compartilhar do horizonte utópico da construção de uma sociedade livre, justa e solidária. E dos objetivos estratégicos: 1) do desenvolvimento nacional de modo sustentável ecologicamente, baseado no desenvolvimento da dignidade da pessoa humana e no aprofundamento da cidadania; 2) da erradicação da pobreza e da marginalização; 3) da redução das desigualdades sociais e regionais; 4) da promoção do bem comum; 5) e do combate a quaisquer formas de preconceitos e discriminação (Constituição da República Federativa do Brasil, arts. $1^{\circ}$ e $\left.3^{\circ}\right)$.

"A utopia está lá no horizonte. Me aproximo dois passos, ela se afasta dois passos. Caminho dez passos e o horizonte corre dez passos. Por mais que eu caminhe, jamais alcançarei. Para que serve a utopia? Serve para isso: para que eu não deixe de caminhar" (GALEANO, 1994). 


\section{O CONCEITO DE CLASSES SUBALTERNAS EM GRAMSCI}

Antonio Gramsci desenvolve a categoria de classes subalternas em seus escritos carcerários (1926-1935).

Cabe ressaltar a importância do Caderno 25, intitulado Às margens da história (História dos grupos sociais subalternos), em relação ao conceito gramsciano de classes subalternas, onde pode-se ser encontrada uma inovadora análise crítica acerca dos grupos sociais subalternos, sobre os modos de se resgatar a sua história, e, principalmente, sobre como unificar suas lutas com o objetivo de construir a hegemonia popular, a partir de uma nova concepção de Estado e de sociedade (SEMERARO, 2011, p. 290).

No Caderno 25, §5., o marxista italiano diz que

As classes subalternas, por definição, não são unificadas e não podem se unificar enquanto não puderem se tornar "Estado": sua história, portanto está entrelaçada à da sociedade civil, é uma função "desagregada" e descontínua da história da sociedade civil e, por este caminho, da história dos Estados ou grupos de Estados (GRAMSCI, 2002, p. 139-140).

Como explica Giovanni Semeraro (2011, p. 296-297), acerca do citado $\S$ 5., intitulado Critérios de método,

No entanto, diversamente das posições liberais que consideram o Estado como um aparelho exterior de caráter "policial" e um "vigia noturno", voltado a garantir a ordem e a propriedade privada com a violência, Gramsci aponta que os subalternos devem criar uma nova concepção de "Estado". Colocado entre aspas, deixa entender que a sua configuração deve ser profundamente diferente da concepção convencional, burocrática, elitista e autoritária. Ao contrário, desenvolvendo uma linha de pensamento que deriva de Rousseau-HegelMarx, para Gramsci, "tornar-se Estado" não significa estabelecer algo "estático", um modelo predefinido e imposto, mas quer dizer um incessante movimento de construção política, que as "forças populares" devem aprender a conduzir de forma histórica e coletiva. Para sair da condição de "súditos" e de cidadãos formais, os subalternos precisam se unificar e afirmar a sua hegemonia ao "fundar novos estados", assumindo 
livre e criativamente suas responsabilidades sociopolíticas em um "Estado ético-político" efetivamente democrático e universalizador.

O significado mais realista de democracia - na obra de Gramsci - está ligado, sem dúvida, ao conceito de hegemonia. A existência real de democracia entre dirigentes e dirigidos, governantes e governados, imprescinde da concreta passagem molecular dos grupos dirigidos para o grupo dirigente, favorecida pelo desenvolvimento da economia, e, consequentemente, pelo direito que expressa este desenvolvimento (GRAMSCI, 2007, p. 287).

Em suas notas carcerárias, o ex-secretário geral do Partido Comunista Italiano ensina que

No Oriente, o Estado era tudo, a sociedade civil era primitiva e gelatinosa; no Ocidente, havia entre o Estado e a sociedade civil uma justa relação e, ao oscilar o Estado, podia-se imediatamente reconhecer uma robusta estrutura da sociedade civil. O Estado era apenas uma trincheira avançada, por trás da qual se situava uma robusta cadeia de fortalezas e casamatas; em medida diversa de Estado para Estado, é claro, mas exatamente isto exigia um acurado reconhecimento de caráter nacional (GRAMSCI, 2007, p. 262).

O Estado pode ser simbolizado pela figura do centauro, onde sua metade animal refere-se ao aspecto da força e da dominação, exercidos pela figura do Estado-coerção (como sinônimo de sociedade política), enquanto sua metade humana refere-se ao aspecto do consenso e da hegemonia, desenvolvidas no campo do Estado-ético (como sinônimo de sociedade civil). Para Gramsci, o Estado se ampliou, podendo ser sintetizado na fórmula de "hegemonia couraçada de coerção", tendo os aparelhos burocrático-executivos e coercitivos na esfera da sociedade política e os aparelhos privados de hegemonia na esfera da sociedade civil (GRAMSCI, 2007, p. 244).

Como bem sintetiza Carlos Nelson Coutinho (1980, p. 52),

Nesse sentido, ambas as esferas servem para conservar ou promover uma determinada base econômica, de acordo com 
os interesses de uma classe social fundamental. Mas o modo de encaminhar essa promoção ou conservação varia nos dois casos. No âmbito da sociedade civil, as classes buscam exercer sua hegemonia, isto é, buscam ganhar aliados para as suas posições através da direção e do consenso. Por meio da sociedade política, ao contrário, exerce-se sempre uma ditadura, ou, mais precisamente uma dominação mediante a coerção.

$\mathrm{Na}$ acepção gramsciana de Estado ampliado, "a base histórica do Estado se deslocou" colocando "um novo problema de hegemonia", originado a partir da separação entre sociedade civil e sociedade política. Constituindo, assim, "uma forma extrema de sociedade política", na qual sua função é dúplice, no sentido de ora "lutar contra o novo e conservar o que oscila, fortalecendo-o coercitivamente", ora atuar "como expressão do novo para esmagar as resistências que encontra ao desenvolver-se" (GRAMSCI, 2007, p. 262-263).

Como fica, então, a posição dos defensores dos Direitos Humanos diante das classes sociais existentes?

A luta dos militantes dos Direitos Humanos deve se dar a favor e lado a lado das classes subalternas, com a preocupação em dar voz e vez ao grito dos oprimidos.

Dentro da tradição marxista, o autor dos Cadernos do cárcere desenvolve a concepção de democracia e de Estado mais adequadas à posição dos defensores dos Direitos Humanos voltados às classes subalternas, a partir de um saber-fazer desenvolvido com base no paradigma da filosofia da práxis em conjunto com a pedagogia de Paulo Freire, fundada na dialogicidade e comunicação.

\section{A IGUALDADE E O RECONHECIMENTO DA DIFERENÇA EM BOAVENTURA DE SOUSA SANTOS}

Para Boaventura, "a busca de uma concepção contra-hegemônica dos direitos humanos deve começar por uma hermenêutica de suspeita em relação aos direitos humanos tal como são convencionalmente entendidos e 
defendidos". Em outras palavras, e de modo mais direto, é preciso questionar as "concepções dos direitos humanos mais diretamente vinculadas à sua matriz liberal e ocidental" (SANTOS, 2013, p. 43).

A universalidade dos Direitos Humanos pode ser confundida com neutralidade e/ou indiferença em relação ao conflito histórico entre as classes sociais fundamentais?

A concepção liberal e ocidental dos direitos humanos nega a historicidade dos direitos humanos ao defender o postulado de sua universalidade, desse modo, o estatuto ontológico dos direitos humanos não recebe a interferência das contradições e condições históricas.

A categoria marxiana de historicidade deixa clara a importância das condições históricas, as quais limitam toda a existência humana e qualquer formulação abstrata, tanto no plano material, quanto no racional. Desse modo, as ideias e os conceitos possuem sua validade condicionada e limitada por sua determinada época histórica.

Em sua Introdução à Crítica da economia política, Karl Marx (1982a, p. 17) diz que

[...] até as categorias abstratas - precisamente por causa de sua natureza abstrata -, apesar de sua validade para todas as épocas, são contudo, na determinidade dessa abstração, igualmente produto de condições históricas, e não possuem plena validez senão para essas condições e dentro dos limites destas.

Para Michael Löwy (1998, p. 15), a historicidade mostra "que não existem princípios eternos, nem verdades absolutas, todas as teorias, doutrinas e interpretações de realidade, têm que ser vistas na sua limitação histórica".

Marx deixa claro que não é possível entender o ser humano ou analisar um período histórico a partir de seu próprio pensamento abstrato, por isso se faz necessário explicar a realidade e a vida humana a partir de suas contradições e de seus conflitos que ocorrem na vida material e nas relações sociais concretas. Isto é, entender que uma "análise dialética é sempre uma análise das contradições internas da realidade" (LÖWY, 1998, p. 16). 
A categoria da contradição na obra marxiana pode ser evidenciada em um trecho do Prefácio à Crítica da Economia Política de 1859, no qual se afirma que

\begin{abstract}
Assim como não se julga o que um indivíduo é a partir do julgamento que ele faz de si mesmo, da mesma maneira não se pode julgar uma época de transformação a partir de sua própria consciência; ao contrário, é preciso explicar essa consciência a partir das contradições da vida material, a partir do conflito existente entre as forças produtivas sociais e as relações de produção (MARX, 1982b, p. 25-26).
\end{abstract}

Como bem observa Carlos Nelson Coutinho, a dialética "não pensa 0 todo negando as partes, nem pensa as partes abstraídas do todo. Ela pensa tanto as contradições entre as partes (a diferença entre elas [...]) como a união entre elas ([...] se relacionarem no seio da sociedade enquanto totalidade)". (Apud KONDER, 1998, p. 46)

$\mathrm{Na}$ visão convencional e eurocêntrica dos direitos humanos, o princípio da igualdade está baseado numa igualdade meramente formal, de caráter jurídico-política, e não numa igualdade substancial que leve também em consideração os aspectos sociais, econômicos e culturais da vida humana; ou seja, a igualdade liberal é restrita a todos serem considerados iguais perante a lei, sem levar em conta que no cotidiano a lei não é aplicada de maneira igual para todos (SANTOS, 2013, p. 78).

Sobre o princípio do reconhecimento da diferença, inserido numa concepção contra-hegemônica dos direitos humanos, o autor português afirma que

A partir de então a luta contra a discriminação e a exclusão deixou de ser uma luta pela integração e pela assimilação na cultura dominante e nas instituições suas subsidiárias, para passar a ser uma luta pelo reconhecimento da diferença, pela consequente transformação da cultura e das instituições de modo a separar as diferenças (a respeitar) das hierarquias (a eliminar) que atavicamente the estavam referidas (SANTOS, 2013, p. 79) 
Logo, é importante reconhecer a necessidade dos educadores populares em Direitos Humanos trabalharem, simultaneamente, com os princípios da igualdade e do reconhecimento da diferença, sintetizado no aforismo: "Temos direito a ser iguais quando a nossa diferença nos inferioriza; e temos o direito a ser diferentes quando a nossa igualdade nos descaracteriza" (SANTOS, 2003, p. 56).

\section{A COMUNICAÇÃO E A DIALOGICIDADE EM PAULO FREIRE}

Para Paulo Freire, "o homem como um ser de relações, desafiado pela natureza, a transforma com seu trabalho" e "o resultado desta transformação, que se separa do homem, constitui seu mundo". Logo, "o mundo da cultura" prolonga-se "no mundo da história"; e "o mundo social e humano, não existiria como tal se não fosse um mundo de comunicabilidade fora do qual é impossível dar-se o conhecimento humano". Sendo a intersubjetividade ou a intercomunicabilidade "a característica primordial deste mundo cultural e histórico" (FREIRE, 1977, p. 65).

A relação com o subalterno deve ser de aproximação dialógica e comunicativa, com intuito de compartilhar os conhecimentos seus e dele, numa relação pedagógica, onde ambos são - ao mesmo tempo - educadoreducando e educando-educador.

Para haver a comunicação é imprescindível a existência de laços de reciprocidade, só sendo possível compreender o pensamento dentro de sua dupla função: cognoscitiva e comunicativa. Porém, esta função não pode ser caracterizada como "a extensão do conteúdo significante do significado, objeto do pensar e do conhecer" (FREIRE, 1977, p. 67).

Nesse sentido, "comunicar é comunicar-se em tôrno do significado significante". Por isso, "na comunicação, não há sujeitos passivos", pelo contrário, "os sujeitos co-intencionados ao objeto de seu pensar se comunicam seu conteúdo". Assim, a comunicação, no sentido de "comunicar-se comunicando", é diálogo, e esse diálogo é comunicativo (FREIRE, 1977, p. 67). 
Assim, refutando a passividade e imprescindindo da reciprocidade, é possível desenvolver um trabalho conjunto e coletivo, que busque e construa democrática e horizontalmente os caminhos e as possíveis soluções para as demandas populares.

$\mathrm{Na}$ acepção freiriana, "A educação é comunicação, é diálogo, na medida em que não é transferência de saber", ao contrário, é caracterizada pelo "encontro de sujeitos interlocutores que buscam a significação dos significados" (FREIRE, 1977, p. 69).

Como lidar com o conhecimento em um projeto de assessoria jurídica e educação popular em Direitos Humanos?

É imprescindível reconhecer o outro como igual numa relação de horizontalidade, na qual "um homem só tem direito a olhar o outro de cima para baixo, quando vai ajudá-lo a levantar-se" (Gabriel García Márquez).

\section{A CONSTRUÇÃO DE UMA SOCIEDADE LIVRE, JUSTA E SOLIDÁRIA COMO OBJETIVO ESTRATÉGICO}

O objetivo estratégico encontra-se, de modo abstrato, sintetizado no artigo 3ำ da Constituição da República Federativa do Brasil: "construção da sociedade livre, justa e solidária, na qual o desenvolvimento socioeconômico deve estar voltado necessariamente à erradicação da pobreza e da marginalização, à redução das desigualdades sociais e regionais e à promoção do bem de todos, sem preconceitos e discriminação" (GOULART, 2013, p. 108).

Para Marcelo Goulart (2013, p. 106),

A construção da sociedade democrática supõe o processo democrático que garanta as condições de igualdade e a paridade de armas entre as forças sociais que, na difusão de seus valores e de suas visões de mundo, disputam a hegemonia no âmbito da sociedade civil (guerra de posição). Para isso é preciso conservar e elevar a outro nível as conquistas da democracia liberal (Estado de Direito) e da democracia social (Estado Providência) e superá-las como forma de atingir estados superiores de participação e equidade social (democracia substantiva). 
Portanto, a dicotomia entre a chamada democracia dos "Modernos" (democracia representativa ou indireta) e a democracia dos "Antigos" (democracia participativa ou direta), na qual se trava uma disputa fratricida para que uma delas vença e retire a outra de circulação, não contribui em nada para o fortalecimento e o aprofundamento de um modelo de democracia real (substancial). Democracia real (substancial) esta que realmente esteja comprometida com a erradicação da pobreza e da marginalização, com a redução das desigualdades sociais e regionais, com a promoção do bem da coletividade e com o combate a quaisquer formas de preconceitos e discriminação.

É necessário, ao contrário, uma síntese dialética entre democracia representativa e democracia participativa. "Portanto, não basta estatuir regras do jogo", como ocorre em boa parte das concepções liberais de democracia. Entretanto, não se trata de negar sua necessidade, apesar de sua insuficiência quando isolada para a existência de uma democracia efetiva (substancial), como faz parte considerável da tradição socialista (COUTINHO, 2006, p. 27).

Para Carlos Nelson Coutinho (2006, p. 27),

É preciso, por um lado, que tais regras sejam efetivamente democráticas, ou seja, que contemplem não só a presença de formas de representação, mas também de institutos de democracia direta, participativa; e, por outro, que exista também as condições jurídicas e econômico-sociais para que tais regras sejam efetivamente cumpridas.

A noção de guerra de posição, nos países capitalistas, pode ser entendida como "a passagem da tática da frente única, entendida em sentido geral, para uma tática determinada, que formule os problemas concretos da vida nacional e opere com base nas forças populares tais como estas foram historicamente constituídas" (GRAMSCI, 2004b, p. 380-381).

Sobre a formulação da estratégia de guerra de posição para as formações sociais "ocidentais", "onde se dá uma relação mais equilibrada entre sociedade civil e sociedade política, ou seja, onde se realizou concretamente a 
"ampliação" do Estado", Gramsci ressalta que "as batalhas devem ser travadas inicialmente no âmbito da sociedade civil, visando à conquista de posições e de espaços [...], da direção político-ideológica e do consenso dos setores majoritários da população, como condição para o acesso ao poder de Estado e para sua posterior conservação" (COUTINHO, 2003, p. 147).

O horizonte utópico da construção da sociedade livre, justa e solidária pode encontrar seu respaldo na categoria gramsciana de sociedade regulada, na qual encontra-se

[...] o elemento Estado-coerção em processo de esgotamento à medida que se afirmam elementos cada vez mais conspícuos de sociedade regulada (ou Estado ético, ou sociedade civil). [...]. Na doutrina do Estado - sociedade regulada, de uma fase em que Estado será igual a Governo, e Estado se identificará com a sociedade civil, dever-se-á passar a uma fase de Estado-guarda-noturno, isto é, de uma organização coercitiva que protegerá o desenvolvimento dos elementos de uma sociedade regulada em contínuo incremento e que, portanto, reduzirá gradualmente suas intervenções autoritárias e coativas (2007, p. 244-245).

A extinção do Estado significa "o desaparecimento progressivo dos mecanismos de coerção", ou seja, a absorção da sociedade política pela sociedade civil, caracterizada pela dissolução e esgotamento do Estadocoerção na sociedade regulada (COUTINHO, 2003, p.138).

Desse modo, as funções da dominação e da força cedem gradualmente lugar à hegemonia e ao consenso, conforme se avança na construção do socialismo democrático. Essa absorção da sociedade política pela sociedade civil está ligada à preocupação de Gramsci com a divisão entre governantes e governados, dirigentes e dirigidos, no sentido de que não seja tida como uma "perpétua divisão do gênero humano", e sim apenas como um dado histórico sob determinadas condicionantes; sendo necessário a luta pela construção da hegemonia popular e democrática com objetivo estratégico de superação dessa divisão histórica (COUTINHO, 2003, p.138).

O dirigente do Partido Comunista Italiano afirma sobre a utopia do socialismo, que "Quando a maioria do proletariado estiver organizada, a vida 
social será mais rica de conteúdo socialista do que é agora; e o processo de socialização irá se intensificando e aperfeiçoando cada vez mais". Desse modo, "O socialismo não se instaura com data marcada, mas é um contínuo devir, um desenvolvimento infinito em regime de liberdade organizada e controlada pela maioria dos cidadãos, ou seja, pelo proletariado" (GRAMSCI, 2004a, p. 209).

O trabalho em conjunto com os oprimidos precisa também compartilhar do horizonte utópico da construção de uma sociedade livre, justa e solidária.

$E$, então, "para que serve a utopia? Serve para isso: para que eu não deixe de caminhar" (GALEANO, 1994).

\section{CONCLUSÃO}

Os defensores dos Direitos Humanos precisam se posicionar a favor e lado a lado das classes subalternas historicamente existentes. Colaborando no sentido de empoderar os oprimidos, para sua tomada de consciência da realidade mediatizada e de emancipação da condição de invisibilidade e vulnerabilidade sociais.

Para tanto, é preciso desenvolver um saber-fazer fundando em uma concepção contra-hegemônica dos Direitos Humanos, tendo como referencial teórico-metodológico a tradição marxista historicista, e como salienta Gramsci (2006a, p. 333)

$\mathrm{Na}$ colocação dos problemas histórico-críticos, não se deve conceber a discussão científica como um processo judiciário, no qual um réu e um promotor, que deve demonstrar, por obrigação de ofício, que o réu é culpado e digno de ser tirado de circulação. Na discussão científica, já que se supõe que o interesse seja a pesquisa da verdade e o progresso da ciência, demonstra ser mais "avançado" quem se coloca do ponto de vista de que o adversário pode expressar uma exigência que deva ser incorporada, ainda que como momento subordinado, na sua própria construção. Compreender e valorizar com realismo a posição e as razões do adversário (e o adversário é, em alguns casos, todo o pensamento passado) significa estar liberto das prisões das ideologias (no sentido pejorativo, de 
cego fanatismo ideológico), isto é, significa colocar-se em um ponto de vista "crítico", o único fecundo na pesquisa científica.

Tal concepção contra-hegemônica dos Direitos Humanos tem como elementos centrais: a historicidade; a filosofia da práxis; a igualdade e 0 reconhecimento da diferença; a comunicação e a dialogicidade; a construção da sociedade livre, justa e solidária. Para tanto, utilizou-se conceitos de Antonio Gramsci, Boaventura de Sousa Santos e Paulo Freire, o que não significa a exclusão de outros autores, como explicitado na análise gramsciana sobre a discussão científica.

Um dos caminhos teórico-prático para fugir de uma posição de neutralidade e/ou indiferença, em relação ao conflito histórico entre as classes sociais fundamentais, pode ser o paradigma da filosofia da práxis de Antonio Gramsci combinada com a pedagogia libertadora de Paulo Freire.

Paulo Freire fundamenta sua pedagogia libertadora num humanismo "que, pretendendo verdadeiramente, a humanização dos homens, rejeita toda a fôrma de manipulação, na medida que esta contradiz sua libertação". Humanismo este "que recusando tanto o desespêro quanto o otimismo ingênuo, é, por isto, esperançosamente crítico". Já esta esperança crítica "repousa numa crença também crítica: a crença em que os homens podem fazer e refazer as coisas; podem transformar o mundo". Por fim, esta crença acredita "que, fazendo e refazendo as coisas e transformando o mundo, os homens podem superar a situação em que estão sendo um quase não ser e passam a ser um estar sendo em busca do ser mais" (FREIRE, 1977, p. 74).

O trabalho em conjunto com os oprimidos precisa também compartilhar do horizonte utópico da construção de uma sociedade livre, justa e solidária. Incorporando a tarefa cotidiana da catarse, como filosofia da "concepção do mundo que representa a vida intelectual e moral (catarse de uma determinada vida prática) de todo um grupo social concebido em movimento e considerado, consequentemente, não apenas em seus interesses atuais e imediatos, mas também nos futuros e mediatos" (GRAMSCI, 2006a, p. 302). 
Nesse sentido,

Pode-se empregar a expressão "catarse" para indicar a passagem do momento meramente econômico (ou egoísticopassional) ao momento ético-político, isto é, a elaboração superior da estrutura em superestrutura na consciência dos homens. Isso significa, também, a passagem do "objetivo ao subjetivo" e da "necessidade à liberdade". A estrutura, de força exterior que esmaga o homem, assimilando-o e o tornando passivo, transforma-se em meio de liberdade, em instrumento para criar uma nova forma ético-política, em origem de novas iniciativas. A fixação do momento "catártico" torna-se assim, parece-me, o ponto de partida de toda a filosofia da práxis; o processo catártico coincide com a cadeia de sínteses que resultam do desenvolvimento dialético. (Recordar os dois pontos entre os quais oscila este processo; que nenhuma sociedade se coloca tarefas para cuja solução já não existam, ou estejam em vias de aparecimento, as condições necessárias e suficientes; - e que nenhuma sociedade deixa de existir antes de haver expressado todo o seu conteúdo potencial). (GRAMSCI, 2006a, p. 314-315)

O autor dos Cadernos do Cárcere, na parte citada entre parênteses, refere-se ao famoso trecho do Prefácio à Crítica da Economia Política de Marx. Trecho este, no qual o alemão "fundador da filosia da práxis", fórmula, de modo sintético, seu conceito de materialismo histórico.

O materialismo histórico explicitado na famosa síntese elaborada por Marx (1982b, p. 25):

Uma formação social nunca perece antes que estejam desenvolvidas todas as forças produtivas para as quais ela é suficientemente desenvolvida, e novas relações de produção mais adiantadas jamais tomarão o lugar, antes que suas condições materiais de existência tenham sido geradas no seio mesmo da velha sociedade. É por isso que a humanidade só se propõe as tarefas que pode resolver, pois, se se considera mais atentamente, se chegará à conclusão de que a própria tarefa só aparece onde as condições materiais de sua solução já existem, ou, pelo menos, são captadas no processo de devir. 
Aqui fica evidenciada a "prioridade metodológica atribuída à Economia Política" pelo método marxiano, tendo "sua explicação ontológica na conclusão de que nela reside a anatomia da sociedade civil, cujo conceito compreende a totalidade das relações materiais de vida". Por isso, essa "dialética entre forças produtivas e relações de produção, bem como entre base econômica e superestrutura ideológica e institucional, determina a sucessão dos modos de produção e das formações sociais". Demonstrando que para Marx "a sociedade burguesa é declarada forma transitória de organização social - a última forma antagônica" (GORENDER, 1982, p. XI).

A postura dos defensores e dos educadores populares a favor dos Direitos Humanos precisa "dirigir violentamente a atenção para o presente assim como é, se se quer transformá-lo” (GRAMSCI, 2007, p. 295).

Nesse sentido, a concepção contra-hegemônica dos Direitos Humanos deve procurar se caracterizar "por duas notas fundamentais, que Romain Rolland resumiu em sua palavra de ordem: 'pessimismo da inteligência e otimismo da vontade'"' (GRAMSCI, 2004a, p. 342).

Segundo Gramsci, "A palavra de ordem 'pessimismo da inteligência, otimismo da vontade' deve ser a palavra de ordem de todo comunista consciente dos esforços e dos sacrifícios que são exigidos a quem voluntariamente assumiu um posto de militante nas fileiras da classe operária". (GRAMSCI, 2006b, p. 321)

O sonho dos defensores dos Direitos Humanos carece de ter um caráter coletivo, pois "sonho que se sonha só, é só um sonho que se sonha só, mas sonho que se sonho junto é realidade" (Raul Seixas).

\section{REFERÊNCIAS BIBLIOGRÁFICAS}

ARRUDA JÚNIOR, E. L. de. Direito moderno e mudança social: ensaios de sociologia jurídica. Belo horizonte: Del Rey, 1997.

CHAUÍ, M.; SANTOS, B. de S. Direitos humanos, democracia e desenvolvimento. São Paulo: Cortez, 2013.

CONSTITUIÇÃO da República Federativa do Brasil. Brasília, DF, 1988. 
COUTINHO, C. N. A democracia como valor universal: notas sobre a questão democrática no Brasil. São Paulo: Ciências Humanas, 1980.

Contra a corrente: ensaios sobre democracia e socialismo. São Paulo: Cortez, 2000.

Gramsci: um estudo sobre seu pensamento político. 2. ed. Rio de Janeiro: Civilização Brasileira, 2003.

2006.

Intervenções: o marxismo na batalha das ideias. São Paulo: Cortez,

. (org.). O leitor de Gramsci: escritos escolhidos 1916-1935. Rio de Janeiro: Civilização Brasileira, 2011.

. Marxismo e política: a dualidade de poderes e outros ensaios. 2. ed. São Paulo: Cortez, 1996.

FREIRE, P. Extensão ou comunicação?. 3. ed. Rio de Janeiro: Paz e Terra, 1977.

GALEANO, Eduardo. As palavras andantes. Porto Alegre: L\&PM, 1994.

GORENDER, J. Introdução. In: MARX, K. Para a Crítica da economia política: salário, preço e lucro; o rendimento e suas fontes: a economia vulgar. São Paulo: Abril Cultural, 1982. p. VII-XXIII. (Coleção Os Economistas)

GOULART, M. P. Elementos para uma teoria geral do Ministério Público. Belo Horizonte: Arraes Editores, 2013.

GRAMSCI, A. Cadernos do cárcere: Introdução ao estudo da filosofia; A filosofia de Benedetto Croce. 4. ed. Rio de Janeiro: Civilização Brasileira, 2006a. v. 1.

Cadernos do cárcere: Os intelectuais; O princípio educativo; Jornalismo. 4. ed. Rio de Janeiro: Civilização Brasileira, 2006b. v. 2.

Cadernos do cárcere: Maquiavel; Notas sobre o Estado e a política. 3. ed. Rio de Janeiro: Civilização Brasileira, 2007. v. 3.

Cadernos do cárcere: O Risorgimento; Notas sobre a história da Itália. Rio de Janeiro: Civilização Brasileira, 2002. v. 5.

Escritos políticos. Rio de Janeiro: Civilização Brasileira, 2004a. v. 1.

Escritos políticos. Rio de Janeiro: Civilização Brasileira, 2004b. v. 2. 
KONDER, L. Em torno de Marx. São Paulo: Boitempo, 2010.

O que é dialética. 28. ed. São Paulo: Brasiliense, 1998. (Coleção Primeiros Passos, 23)

LÖWY, M. Ideologias e ciência social: elementos para uma análise marxista. 12. ed. São Paulo: Cortez, 1998.

MACHADO, A. A. Ensino jurídico e mudança social. 2. ed. São Paulo: Atlas, 2009.

MARX, K. Introdução. In: MARX, K. Para a Crítica da economia política: salário, preço e lucro; o rendimento e suas fontes: a economia vulgar. São Paulo: Abril Cultural, 1982a. p. 3-21. (Coleção Os Economistas).

. Prefácio. In: MARX, K. Para a Crítica da economia política: salário, preço e lucro; o rendimento e suas fontes: a economia vulgar. São Paulo: Abril Cultural, 1982b. p. 23-27. (Coleção Os Economistas)

SANTOS, B. S. (org.). Reconhecer para libertar: os caminhos do cosmopolitismo multicultural. Rio de Janeiro: Civilização Brasileira, 2003.

SEMERARO, G. Gramsci e os movimentos populares: uma leitura a partir do Caderno 25. In: SEMERATO, G. (org.) [et. al.]. Gramsci e os movimentos populares. Niterói: Editora da Universidade Federal Fluminense, 2011. p. 287302.

WOLKMER, Antonio Carlos. Introdução ao pensamento jurídico crítico. 5. ed. rev. São Paulo: Saraiva, 2006. 